Revista Universo Contábil, ISSN 1809-3337

FURB, v. 5, n. 2, p. 39-57, abr./jun., 2009

doi:10.4270/ruc. 2009212

Disponível em www.furb.br/universocontabil

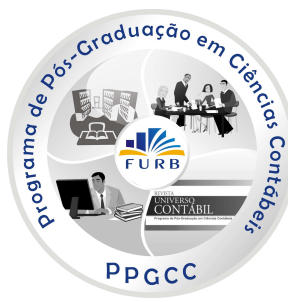

\title{
ANÁLISE DA EFICIÊNCIA EM COOPERATIVAS AGROPECUÁRIAS NO ESTADO DO RIO GRANDE DO SUL*
}

\section{EFFICIENCY ANALYSIS OF AGRICULTURAL COOPERATIVES IN THE STATE OF RIO GRANDE DO SUL}

Breno Augusto Diniz Pereira

Doutor em Administração pela UFRGS

Professor da Universidade Federal de Santa Maria

Endereço: Rua Floriano Peixoto, 1184

CEP: 97015-372 - Santa Maria/RS - Brasil

E-mail: professorbreno@terra.com.br

Telefone: (55) 3220-9258

Jonas Cardona Venturini

Doutorando em Administração pela UFRGS

Professor da Universidade Federal do Rio Grande do Sul

Endereço: Rua Washington Luiz, 855

CEP: 90010-460 - Porto Alegre/RS - Brasil

E-mail: jonasventurini@yahoo.com.br Telefone: (55) 3220-9258

Paulo Sérgio Ceretta

Doutor em Engenharia de Produção pela UFSC Professor da Universidade Federal de Santa Maria

Endereço: Rua Floriano Peixoto, 1184 CEP: 97015-372 - Santa Maria/RS - Brasil

E-mail: ceretta@smail.ufsm.br

Telefone: (55) 3222-3444

\section{Vanessa Rabelo Dutra}

Mestre em Administração pela UFSM Professora da Universidade Federal do Pampa

Endereço: Rua Barão do Triunfo, 1048 CEP: 97573-590 - Santa Maria/RS - Brasil

E-mail: coord_administracao@fapas.edu.br

Telefone: (55) 3243-4540

* Artigo recebido em 23.10.2007. Revisado por pares em 20.04.2008. Reformulado em 10.10.2008. Recomendado em 20.10.2008 por Ilse Maria Beuren (Editora). Publicado em 30.06.2009. Organização responsável pelo periódico: FURB. 


\section{RESUMO}

O presente estudo tem como objetivo principal, avaliar a eficiência nas cinqüenta e uma maiores cooperativas agropecuárias do Rio Grande do Sul, através da aplicação da Análise Envoltória de Dados (DEA). Os dados deste estudo foram obtidos dos relatórios anuais fornecidos pelo OCERGS. Essa entidade disponibiliza, periodicamente, relatórios com diversas informações do setor de cooperativas. Foram coletados dados consolidados para as 51 maiores cooperativas referentes aos anos de 2002, 2003 e 2004. Esse trabalho utilizou a análise por envoltória de dados para avaliar o grau de eficiência relativa em cooperativas ao longo de três anos. O foco do trabalho foi sobre o grau de eficiência total, eficiência gerencial e eficiência de escala. Os resultados obtidos permitem afirmar que o conjunto de cooperativas analisadas está operando de maneira homogênea e com grau de eficiência relativamente elevado ao longo de todo o período. Identificou-se que o maior problema não está relacionado com o grau de eficiência, mas com o crescente aumento de ociosidade na estrutura de capital das cooperativas. Outro aspecto importante está relacionado com o fato de não ter sido identificado uma relação significativa entre indicadores de eficiência e rentabilidade.

Palavras-chave: Análise da Eficiência. Análise Envoltória de Dados. Cooperativas Agropecuárias.

\section{ABSTRACT}

This study has as main objective evaluate the efficiency in the 51 largest agricultural cooperatives in Rio Grande do Sul, by applying Data Envelopment Analysis (DEA). The data for this study were obtained from the annual reports provided by OCERGS. This entity provides, periodically, several reports with information about the cooperative sector. The data was collected from the 51 largest consolidated cooperatives referring to the years 2002, 2003 and 2004. This work used data envelopment analysis to assess the degree of efficiency in cooperatives through these three years. The focus of the work was on the total degree of efficiency, managerial efficiency and scale efficiency. The results show that the number of cooperatives analyzed is operating on a homogeneous and relatively high degree of efficiency throughout the period. It was identified that the biggest problem is not related to the degree of efficiency, but to the growing increase of idleness in the capital structure of cooperatives. Another important aspect is related to the fact that it was not identified a significant relationship between indicators of efficiency and profitability.

Keywords: Efficiency Analysis. Data Envelopment Analysis. Agricultural cooperatives.

\section{INTRODUÇÃO}

Estudos realizados por autores como Benecke (1982), Costa Santos (1993), Zylbersztajn (1995) mostram que no sistema cooperativista não são os princípios ou idéias filosóficas que determinam as normas da vida econômica, mas sim fatores como a gerência competitiva, a legislação e a interferência política e econômica do estado. Isto exige que a teoria do cooperativismo não se ocupe exclusivamente da interpretação da filosofia, mas também da investigação sobre as condições necessárias à estabilidade econômico-financeira e do poder competitivo destas instituições.

Mesmo em países desenvolvidos, como é o caso dos Estados Unidos, as cooperativas agropecuárias, em face da estabilização da sua participação no mercado, já estão revendo seus 
processos, suas tecnologias, reavaliando suas estruturas organizacionais e repensando suas opções estratégicas para tornarem-se mais competitivas (COOK, 1994). No oeste da Europa, as cooperativas agropecuárias, confrontando-se com um número de tendências sociais e econômicas, têm revisado suas estratégias, pois, em muitos casos, é necessário adaptá-las, colocando-se lado a lado com investimentos e requerimento de financiamento extra. Além disso, este desenvolvimento tem colocado especial importância nos conselhos de diretores e executivos das cooperativas (VERHEIJEN; HEIJBROEK, 1995).

No Brasil, manter uma postura mais competitiva requer das organizações cooperativas, além da revisão de seus processos e estratégias, a adoção de "estruturas organizacionais" adequadas aos objetivos da organização e às condições do seu ambiente. Isto se deve ao fato de as crescentes mudanças econômicas, políticas e sociais no cenário atual exigirem revisão das configurações, de maneira a adequá-las ao atual ambiente turbulento e mutável. As organizações do tipo burocrática já não parecem responder adequadamente aos novos valores que vêm sendo progressivamente formados ao longo dos anos; é preciso que novas estruturas organizacionais sejam gradativamente configuradas, considerando esta nova realidade emergente. Nesse sentido, a busca constante pelo aperfeiçoamento de suas operações, visando tornarem-se mais competitivas frente ao mercado concorrencial, força que as cooperativas, de maneira particular as cooperativas agropecuárias utilizem ferramentas que auxiliem na quantificação de sua eficiência, mas mais que isso, que proponha sugestões de melhorias para as organizações.

Ainda nesse contexto, a Análise Envoltória de Dados (DEA) foi proposta originalmente em 1978 por Charnes, Cooper e Rhodes (CHARNES; COOPER; RHODES, 1978) e consiste em determinar a eficiência relativa de uma unidade produtiva, considerandose a aproximação de uma fronteira de eficiência (bases de economia de produção para utilização do DEA podem ser encontradas nos trabalhos de Coelli et al. (1998), De Leone et al. (1999), entre outros). Em termos mais precisos, pode-se dizer que é um método não paramétrico de construção de uma fronteira de eficiência, relativamente à qual se pode estimar a eficiência de cada unidade, e determinar as unidades referenciais para os casos de ineficiência. Embora as aplicações iniciais de DEA tenham sido predominantemente sobre organizações sem fins lucrativos (CHIRIKOS, 2000), existem trabalhos publicados sobre aplicações em instituições diversas para aplicação no setor industrial, para aplicações no setor agrícola, para aplicação no setor de telefonia, para aplicações no setor bancário, entre outros.

O presente estudo teve como objetivo principal, avaliar a eficiência nas 51 maiores cooperativas agropecuárias do Rio Grande do Sul, através da aplicação da Análise Envoltória de Dados (DEA). Para concretizar o objetivo proposto o artigo está estruturado em sete etapas, incluindo as notas introdutórias. A segunda etapa refere-se ao contexto das cooperativas, sua filosofia, passos para a sua constituição, o cooperativismo no Brasil. A terceira aborda sua estrutura organizacional e seus modelos de gestão. A quarta trata da mensuração do desempenho através da análise envoltória de dados DEA. A quinta discorre o método de trabalho. A sexta traz os resultados e a sua discussão. E a sétima, por fim, traz as considerações finais.

\section{COOPERATIVAS}

Uma sociedade cooperativa é uma associação de pessoas que se unem voluntariamente para atingir um fim comum, pela formação de uma organização controlada democrática e participativamente, contribuindo eqüitativamente para o capital demandado, aceitando uma parte justa dos riscos e benefícios dos negócios, nos quais os associados participam ativamente (Recomendação $\mathrm{n}^{\circ}$. 127, de 06/1996, da Organização Internacional do Trabalho). Irion (1997) destaca que as cooperativas se diferenciam das empresas porque uma cooperativa 
é uma sociedade de pessoas e não de capital. O capital é meio e não finalidade e o poder é pessoal, unitário e independente do montante de capitalização de cada indivíduo.

Outra característica das cooperativas que as diferencia fortemente de uma empresa de capital é a sua dupla natureza: onde, de um lado, o grupo cooperativado (a associação) e, do outro, a atividade cooperativa (a empresa) destinada ao serviço das economias individuais associadas. Os associados não são somente co-proprietários, mas também seus usuários. A cooperativa é uma entidade formada pelo agrupamento de pessoas com interesses semelhantes, enquanto a empresa é a unidade econômica criada para produzir bens e/ou serviços requeridos pelos acionistas.

As decisões empresariais nas cooperativas compreendem um universo analítico mais amplo que o das demais empresas, pois o que está em jogo não é só a capacidade de acumulação, crescimento da empresa e consequiente remuneração, mas acima de tudo o crescimento dos associados, enquanto unidades produtivas garantindo a remuneração de seu trabalho. A administração dessa problemática, destacada por Polônio (1999), é fator essencial para o aumento da eficiência empresarial, e passa necessariamente pela capacitação e conscientização dos associados sobre economia e mercado nos quais atuam.

Polônio (1999) ainda destaca que há dois elementos que definem o caráter de uma cooperativa: a) os fins para os quais foi criada; e b) os meios para alcançá-los. Os fins de uma cooperativa estão intimamente relacionados com a sua missão e os seus objetivos definidos estrategicamente na assembléia geral. Já os meios estão sujeitos a um processo dinâmico de mudanças, no qual a tomada de decisão e a conduta dos administradores têm importância fundamental, mesmo quando não seja produto espontâneo da interação social, uma vez que tenham sido definidos a priori para guiar as atividades da organização.

Os meios são representados pela estrutura da organização e as normas que as regem, razão pela qual no formato organizacional das cooperativas agropecuárias brasileiras existem algumas estruturas comuns e que predominam, devido determinação legal, para que estas organizações funcionem e se constituem em espaços de participação dos associados com destaque para:

a) Assembléia geral - A assembléia é o órgão supremo de uma cooperativa, na qual cada associado tem poder igual, cada associado um voto, independentemente do número de quota que possua, e constitui-se um espaço de decisões relacionadas às estratégias, políticas, modelo operacional, enfim, tudo que concerne ao funcionamento da organização (POLÔNIO, 1999);

b) Conselho administrativo - formado por associados, eleito pelos sócios de forma direta, cuja função é de administração, (BIALOSKORSKI, 1998). Além disso, exerce as funções de direção e representação da cooperativa e, através da gerência executiva, implementa as ações acordadas nas assembléias gerais;

c) Conselho fiscal - Órgão de aferição, de auditoria, de acompanhamento, de avaliação e de averiguação. Eleito pela assembléia geral para acompanhar permanentemente o desempenho da sociedade, dos sócios e dos dirigentes, independente do conselho administrativo, com representação dos associados, atuando como fiscalizador dos administradores eleitos e ou contratados, (BIALOSKORSKI, 1998).

Existem diversos outros instrumentos que atualmente estão sendo colocados em prática pelas cooperativas agropecuárias brasileiras visando criar maiores condições para participação dos associados. A seguir serão relacionados alguns desses com o propósito de realizar um paralelo entre as informações relatadas e os resultados observados em campo nas cooperativas agropecuárias do Estado do Rio Grande do Sul, no que se refere à utilização de instrumentos descentralizados de participação diferentes das assembléias gerais que estão sendo utilizados pelas mencionadas organizações. 
a) Conselhos de associados - constituem-se de conselhos organizados pelos associados que congregam entes de uma mesma comunidade ou pessoas que se dedicam a uma determinada atividade comum. Este tipo de estrutura facilita o processo de decisão, pois, para cada conselho, é eleito um representante que tem como função discutir diretamente com o Conselho de Administração, e representar na Assembléia Geral os interesses e propostas emanadas dos conselhos dos cooperados, constituindo-se num elo entre o associado e a administração da cooperativa, contribuindo de forma direta para agilizar o processo decisório;

b) Conselho de líderes - conforme mencionado no item anterior, em cada conselho de cooperados é eleito um líder, e este passa a compor o conselho de líderes, cujo principal papel é o de discutir as diversas propostas emanadas daquele colegiado, de sorte que seja levada à assembléia geral uma proposta consolidada que represente o pensamento de todos os associados e que já foi discutida previamente. Este fato é importante, pois nem sempre é possível consultar todos os cooperados a todo o momento, pois o número é elevado. Neste caso, a consulta é feita diretamente ao conselho de líderes;

c) Conselho de ética cooperativista - tem como objetivo avaliar e propor correções ao sistema, constituindo-se um instrumento balizador do comportamento dos associados e dirigentes das cooperativas. Por isso mesmo se apresenta como elemento de grande valia para o desenvolvimento e aperfeiçoamento da autofiscalização, através da análise dos desvios dos objetivos e das denúncias dos associados (PINHO, 1972).

\subsection{Cooperativismo no Brasil}

O interesse pelo movimento cooperativo no Brasil tem raízes antigas. Maurer Jr. (1966) destaca que se pode encontrar em 1610 a construção de um estado cooperativo em bases integrais através da fundação das primeiras reduções jesuíticas. Por mais de 150 anos, esse modelo deu exemplo de produção solidária fundamentada no trabalho coletivo, no qual o bem estar do indivíduo e da família se sobrepunham ao interesse econômico da produção. A ação dos padres jesuítas se baseou na persuasão, movida pelo amor cristão e no auxílio mútuo, prática encontrada entre os indígenas brasileiros e em quase todos os povos primitivos dos primeiros tempos da humanidade.

Porém, a formalização do movimento cooperativista no Brasil inicia-se em 1847, com o médico francês Jean Maurice Faivre. Adepto das idéias reformadoras de Charles Fourier, Faivre fundou, com um grupo de europeus, nos sertões do Paraná, a colônia Tereza Cristina, organizada em bases cooperativas. Essa organização, apesar de sua breve existência, representa o elemento formador do cooperativismo brasileiro.

Pereira (1993) destaca que antes de 1888, as condições para implantação do sistema cooperativista no Brasil eram precárias, principalmente em função da maioria da mão-de-obra ser escrava. Melhorias dessas condições só ocorreram no final do século XIX devido, principalmente, a nova situação sócio-econômica criada com a abolição da escravatura.

Segundo Oliveira (1996), a legislação das cooperativas de trabalho no Brasil se consolidou pelo art.24 do Decreto- Lei $n^{\circ}$. 22.232, de 19/12/32:

São Cooperativas de trabalho aquelas que constituídas entre operários de uma determinada profissão ou oficio ou de ofícios vários de uma mesma classe, têm como finalidade primordial melhorar salários e as condições de trabalho pessoal de seus associados e, dispensando a intervenção de um patrão ou empresário, se 
propõem contratar obras, tarefas, trabalhos ou serviços públicos ou particulares, coletivamente por todos ou por grupos de alguns (OLIVEIRA, 1996, p. 37).

As cooperativas de trabalho surgem como forma de reverter o quadro de desemprego da sociedade atual, a reunião de trabalhadores com o fim de fazer uma conexão entre o mercado e o trabalhador. Segundo Irion (1997), o cooperativismo deverá ter por base a posse privada dos meios de produção, um planejamento descentralizado e individualizado centrado na cooperativa e no cooperado. É conforme sua conceituação:

[...] uma associação autônoma de pessoas que se uniram voluntariamente para fazer frente às necessidades e aspirações econômicas, sociais e culturais comuns por meio de uma empresa de propriedade conjunta e democraticamente controlada (IRION, 1997, p. 47).

Foi a partir de 1988 que o governo fomentou o cooperativismo, garantindo a sua autogestão. Assim, a legislação (Lei $\mathrm{n}^{\circ}$. 5.764/71) que apóia a formação do cooperativismo está no art. 174 da Constituição Federal, em seu $2^{\circ}$ parágrafo. As cooperativas de trabalho têm um fim social, são criadas para servir, fornecer serviço confiável e de boa qualidade. Seu estatuto deve conter a forma como o associado participará desta, com suas obrigações e direitos, esta não deve visar o lucro, deve ter o objetivo de eliminar a intermediação entre o associado e o tomador.

A Aliança Cooperativista Internacional (ACI), sediada em Brasília, tem registrado cerca de 750 milhões de pessoas ligadas ao cooperativismo no mundo. No Brasil, a Organização das Cooperativas do Brasil (OCB) registra a existência de 5.652 cooperativas envolvendo 5.014.016 associados (OCERGS, 1999).

Em 1980, no Brasil, existiam 60 cooperativas de trabalho, número esse que passou para 82 em 1990 e para 7.130 até dezembro de 2004 (OCB, 2004). Muitas delas não atuam dentro do ideário cooperativista, servindo de "fachada" para burlar a lei. Por outro lado, verdadeiras cooperativas de trabalho lutam com dificuldades para se manterem no mercado diante da concorrência das falsas cooperativas. A Figura 1 demonstra a evolução das cooperativas por Estado, destacando os que apresentaram maior evolução na criação de novas cooperativas.

As cooperativas agropecuárias surgiram e se consolidaram numa economia predominantemente agrária e exportadora e, de certa forma, refletem o sistema patriarcal que marcou a organização da sociedade brasileira e discriminou o trabalho da mulher. Em dezembro de 2004, de acordo com a OCB, essas cooperativas representavam 19,6\% do total de cooperativas brasileiras, registrando 1.398 cooperativas em atividade, congregavam $14,1 \%$ do total de associados, com um montante de 865.173 pessoas e eram responsáveis por $60 \%$ dos empregos gerados pelo sistema cooperativo brasileiro, com um total de 116.919 empregados. 


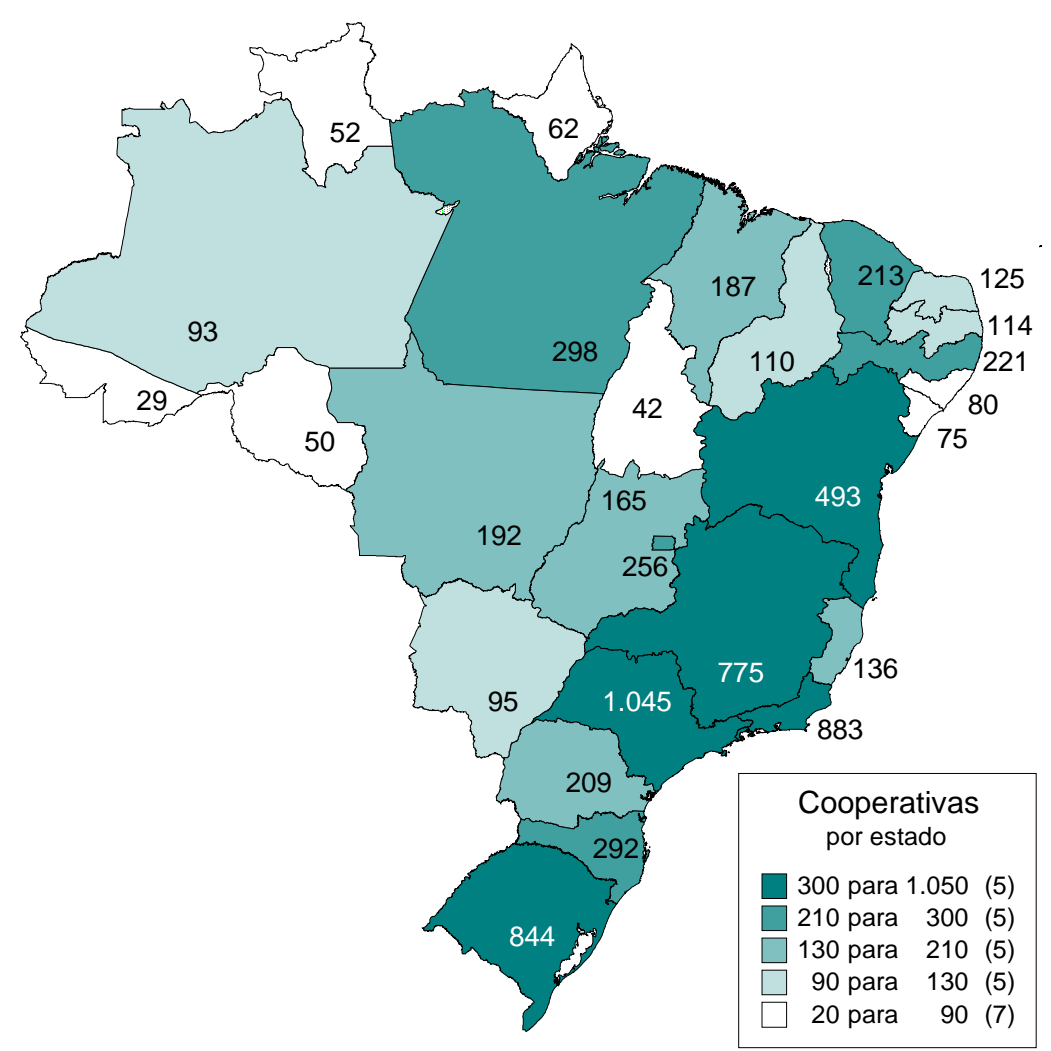

Figura 1: Número de cooperativas por Estado Fonte: OCB (2004).

No que se refere a participação das cooperativas agropecuárias na produção, mais uma vez as cooperativas ressaltam sua importância para a economia nacional. A Figura 2 apresenta alguns números da participação das cooperativas agropecuárias na economia do Brasil.

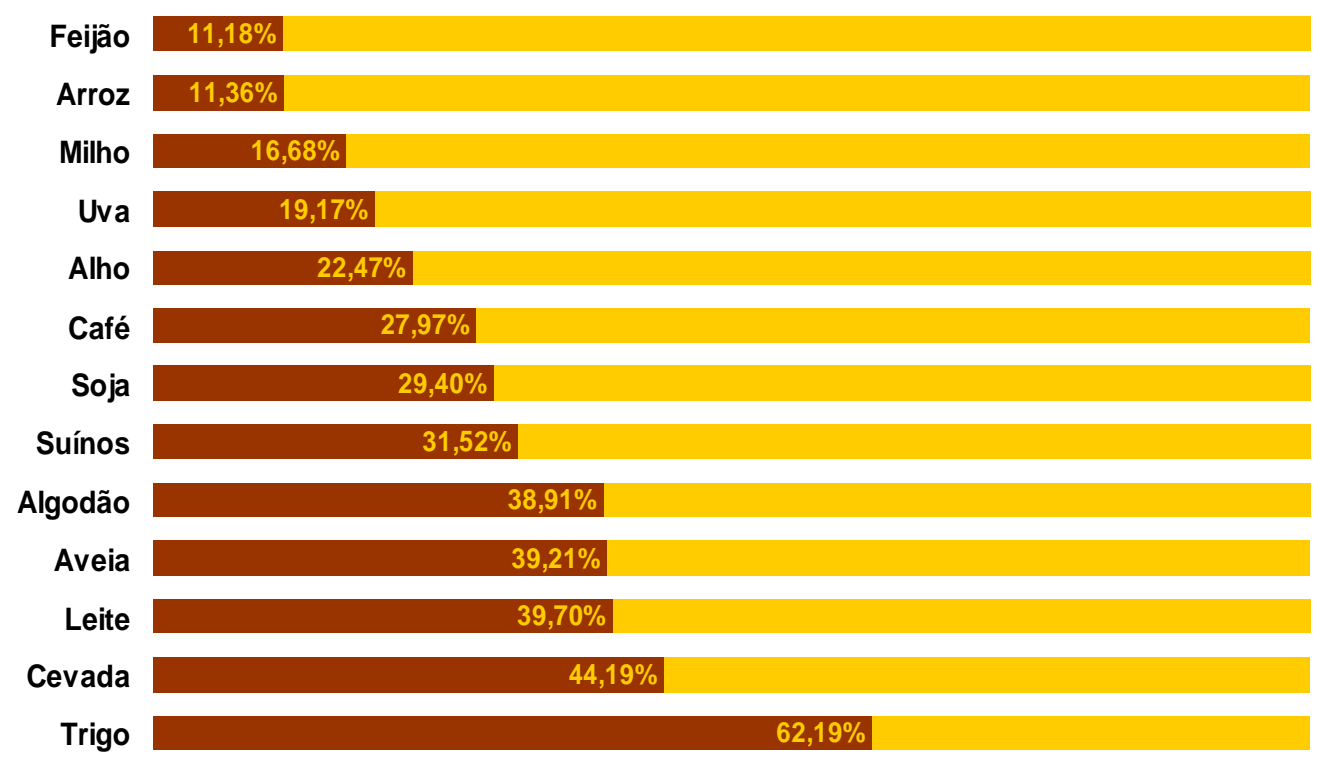

Figura 2: Participação das cooperativas agropecuárias na economia agrícola nacional Fonte: OCB (2004). 


\section{ESTRUTURA ORGANIZACIONAL E O MODELO DE GESTÃO DAS COOPERATIVAS}

O modelo de gestão das cooperativas brasileiras vem recebendo muitas críticas por apresentar várias deficiências que vêm comprometendo a competitividade dessas organizações, principalmente, devido à ineficácia administrativa apresentada, que pode colocar em risco a sobrevivência dessas organizações. Entre os problemas citados por diversos autores como Lauschner e Schweinberger (1989), Schulze (1987), Antonello (1995), Bernardo (1996), Telma (1997), Antonialli (1998) e Bastos (2002), podem-se listar: a lentidão nas decisões por envolver consenso entre os cooperados (decisão colegiada e burocrática); a falta de competência administrativa dos dirigentes (baixa profissionalização); centralização do poder; o rodízio no poder entre um grupo de associados; a remuneração demasiada dos dirigentes, motivando-os a serem assalariados em vez de produtores; a reduzida participação dos associados nas assembléias e, finalmente, a falta de planejamento de longo prazo.

De acordo com Jank e Nassar (1995), muitas cooperativas agropecuárias estão enfrentando sérios problemas na atualidade como a perda dos maiores produtores para as empresas privadas, a ausência de profissionalização dos quadros de dirigentes e a falta de orientação para o mercado. Os autores sugerem as seguintes soluções para os problemas do cooperativismo: a) seleção de cooperados ativos, com base no grau de fidelidade, comprometimento e eficiência econômica; b) eliminação do princípio de "livre entrada" na cooperativa, definindo-se padrões rígidos de participação no negócio; c) profissionalização da gerência operacional, desenvolvendo sistemas rígidos de controle e avaliação, inclusive dos conselhos de administração e fiscal; d) desenvolvimento de alianças estratégicas com outras empresas e terceirizações; e) introdução de novos critérios de pagamento dos cooperados, ou valorizar o indivíduo que traz mais benefícios em termos de volume, qualidade e regularidade de entrega do produto; f) encontrar formas de acesso ao capital externo de risco, visando à capitalização da cooperativa; g) gerenciar o processo de diversificação dos negócios e de adição de valor ao produto e finalmente; $h$ ) discutir novos critérios de votação em assembléia, que favoreçam o desempenho econômico e, em caso de sucessão, a continuidade das diretrizes estabelecidas na gestão anterior.

A Constituição Federal de 1988 representou um importante momento para o cooperativismo brasileiro, quando foi vedada a interferência estatal no funcionamento das cooperativas (BRASIL, 1988). Dessa forma, com a nova Constituição, as cooperativas conquistaram o direito à autogestão. Pereira (1993) afirma que a palavra autogestão pode ser entendida como sendo o governo de si mesmo e etimologicamente significa a administração por conta própria, sem intervenção por parte de terceiros. Segundo a OCEPAR (1992), a autogestão originada da Constituição de 1988 representou uma maior liberdade às cooperativas, porém, delega ao cooperativismo uma enorme responsabilidade em relação ao seu próprio futuro, ou seja, por consequiência demanda uma maior organização interna.

$\mathrm{Na}$ esteira do programa de autogestão surgiram movimentos relacionados à reestruturação organizacional das empresas cooperativas e a profissionalização da administração. Granthom (1987), Crúzio (1989) e Bialoskorski Neto e Zylbersztajn (1994) abordam em seus trabalhos a questão da capacidade profissional dos dirigentes de cooperativas em administrá-las e ressalta tratar-se de organizações complexas, o que evidencia a importância e a necessidade de seus gestores serem capacitados profissionalmente.

\section{MENSURAÇÃO DO DESEMPENHO ATRAVÉS DA DEA}

Os principais fatores de análise são aqueles que trazem vantagem competitiva para as empresas, ou seja, são os fatores que precisam estar representados nas medidas de desempenho, pois os competidores que melhor se comportarem em relação a estes fatores 
terão maiores chances de sucesso. Só é possível determinar se uma empresa é eficiente ou não, através da mensuração do seu desempenho, extraindo-se a evolução e a consequiente comparação com períodos anteriores.

Considerando as dificuldades e deficiências das análises tradicionais, o presente estudo apresenta uma contribuição à avaliação do desempenho de 51 maiores cooperativas do Estado do Rio Grande do Sul, através do relatório anual fornecido pela OCERGS para as cooperativas do Estado. Esse relatório faz uma abordagem no que se refere aos demonstrativos financeiros, na qual se destaca as análises dos índices financeiros. Neste estudo, destaca-se a utilização da Análise Envoltória de Dados (DEA), aplicada às Demonstrações Contábeis, explorando as suas vantagens. Essa ferramenta determina a eficiência relativa de cada unidade em análise, comparando-a com as demais. O modelo DEA usado leva em conta os retornos de escala, através da comparação de cada empresa com as que operam em escala semelhante. A sistemática de cálculo envolve vários fatores somados que ao final trazem informações de maior consistência para a determinação do desempenho e tomada de decisões.

A expressão avaliação de desempenho, segundo Catelli (1999), pode assumir diversos significados, dependendo do sentido conferido ao termo avaliação e do contexto relativo ao desempenho, objeto dessa avaliação. Avaliar um desempenho significa julgá-lo ou atribuir-lhe um conceito diante de expectativas preestabelecidas. Entretanto, ao mesmo tempo em que essa afirmativa transmite um significado da expressão avaliação de desempenho, pode induzir ao entendimento de que, no contexto empresarial, seja esse o maior propósito a ser alcançado na implementação do conceito, o que pode provocar conseqüências danosas.

No âmbito empresarial, em sentido genérico, o analista é aquele profissional que desenvolve a análise de uma empresa, tendo como ponto de partida as demonstrações contábeis, as quais fornecem um conjunto de números e informações sobre a situação patrimonial, econômica e financeira da empresa. Ao expor sua idéia sobre o comportamento dos investidores, Silva (2004) enfatiza que é desenvolvida uma análise de alternativas de investimentos a qual envolve o binômio risco-retorno. Dessa forma, antes de investir seu dinheiro, o investidor precisa saber qual o retorno esperado daquela aplicação e, ao mesmo tempo, é necessário que ele saiba qual o risco associado ao investimento. Quanto maior for o risco, maior será o retorno exigido pelo investidor. Essa análise é pertinente sob a perspectiva dos investidores com expectativas racionais.

O processo de mensurar o desempenho organizacional é um processo permanente e repetitivo, onde a freqüência das medições depende da atividade a ser medida. Há várias razões pelas quais se mede o desempenho. As mais importantes consistem em monitorar o progresso da empresa e corrigir eventuais erros. Não existe até hoje, segundo Schmidt (2003), nenhum método ou modelo de avaliação de desempenho organizacional que seja único para toda e qualquer organização. Em vez disso, os gestores e analistas utilizam uma série de metodologias de avaliação de desempenho para lidar com os diferentes elementos de uma organização.

Contudo, os métodos que consideram aspectos diversificados tendem a assumir uma importância especial, já que o desempenho acaba sendo afetado por variáveis de diferentes naturezas. Esse tipo de metodologia multicriterial é sempre crucial num processo de avaliação institucional. Com essa multiplicidade de fatores de decisão, faz-se necessário o uso de métodos e técnicas que possam proporcionar aos gestores uma melhor percepção do desempenho organizacional.

É justamente nesse sentido, no entendimento de Macedo e Macedo (2003), que foi desenvolvida a DEA, uma técnica com capacidade de comparar a eficiência de múltiplas unidades operacionais similares (homogêneas) mediante a consideração explícita do uso de suas múltiplas entradas (recursos) na produção de múltiplas saídas (produtos). Essa técnica é 
denominada de Análise Envoltória de Dados (DEA), e pode ser utilizada para comparar um grupo de empresas ou unidades de negócio a fim de identificar as eficientes e as ineficientes, em termos relativos, medindo a magnitude das ineficiências e descobrindo formas para reduzi-las pela comparação destas com as eficientes.

A Análise Envoltória de Dados, segundo Zhu (2000) representa uma das mais adequadas ferramentas para avaliar a eficiência, em comparação com ferramentas convencionais. Os resultados da DEA são mais detalhados do que os obtidos em outras abordagens, servindo melhor ao embasamento de recomendações de natureza gerencial. Na abordagem DEA, a análise de eficiência de empresas com múltiplos insumos e produtos parte da idéia de construir uma superfície limite, de tal modo que as empresas mais eficientes se situem sobre esta superfície, enquanto as menos eficientes se situem abaixo dela. Então, o grau de ineficiência de uma empresa qualquer do conjunto pode ser avaliado como a distância do vetor produto/insumo até a superfície de referência.

Para a obtenção dos resultados a partir do modelo DEA proposto, parte-se do princípio de que o grau de eficiência pode ser medido extraindo-se a proporcionalidade entre a capacidade de geração de receita de cada cooperativa através da utilização de uma variedade de insumos, com o patrimônio líquido, os gastos operacionais e as exigibilidades. Mais precisamente foram utilizados dois modelos básicos de análise por envoltória de dados para obter o indicador de eficiência total e um indicador de eficiência gerencial.

\section{a) Eficiência total}

O cálculo da eficiência total considera que as proporções entre as variáveis observadas permanecem constantes para qualquer porte de organização. Portanto, o índice de eficiência representa o grau de alavancagem necessário nos produtos para projetar a cooperativa até a superfície eficiente (orientado para output), ou o grau de redução nos insumos com a manutenção dos produtos nos mesmos patamares (orientado para input). A técnica DEA apenas indica o quanto essa cooperativa precisa evoluir, e em que fatores de inputs ou outputs, para alcançar o nível de desempenho daqueles considerados eficientes, indicador igual à unidade, ou seja, $100 \%$ eficiente. O método utilizado para a eficiência total será o CCR, orientado para inputs.

\section{b) Eficiência gerencial}

O modelo que considera o aspecto gerencial avalia, de forma rudimentar, a capacidade de a empresa operar com os recursos de que dispunha. No modelo BCC, o qual considera o retorno de escala variável, entende-se que unidades de porte diferente podem operar eficientemente em regiões de escalas diferentes. Assim, adota-se para eficiência gerencial o modelo BCC, orientado para outputs. O índice de eficiência gerencial identifica o valor cujos resultados da empresa analisada deverão ser multiplicados, projetando-a até a superfície eficiente. É tida como uma habilidade gerencial por admitir restrições mais flexíveis quanto à manutenção de produtividade em diferentes níveis de operação.

\section{ASPECTOS METODOLÓGICOS}

Os dados necessários para a realização deste estudo foram obtidos dos relatórios anuais fornecidos pelo OCERGS. Essa entidade, que tem como finalidade básica gerenciar e dar suporte às cooperativas do Estado do Rio Grande do Sul, disponibiliza, periodicamente, relatórios com diversas informações do setor de cooperativas. Foram coletados dados consolidados para as 51 maiores cooperativas referentes aos anos de 2002, 2003 e 2004, conforme critérios definidos pela OCERGS. 
As variáveis que serão considerados no estudo são: receitas (outputs); patrimônio líquido, Gastos operacionais, exigibilidades (inputs) e sobras ou perdas (rentabilidade), sendo essa última, uma variável utilizada para o cálculo da rentabilidade das cooperativas, para assim, fazer o cruzamento com indicadores de eficiência, uma vez que esses são os dados disponíveis na entidade. A Tabela 1 apresenta a estatística descritiva dos dados em dólar americano para estas variáveis.

Tabela 1 - Estatística descritiva das variáveis para as cooperativas

\begin{tabular}{|c|c|c|c|c|c|}
\hline Estatística & Receitas & $\begin{array}{l}\text { Patrimônio } \\
\text { Líquido }\end{array}$ & $\begin{array}{c}\text { Gastos } \\
\text { Operacionais }\end{array}$ & Exigibilidades & $\begin{array}{l}\text { Sobras ou } \\
\text { Perdas }\end{array}$ \\
\hline \multicolumn{6}{|c|}{ Valores relativos ao ano de 2002} \\
\hline Média & 26.910 .992 & 4.547 .359 & 25.557 .959 & 8.554 .957 & 267.733 \\
\hline Máximo & 149.974 .977 & 48.329 .281 & 148.506 .318 & 54.612 .088 & 4.136 .110 \\
\hline Mínimo & 546.362 & 23.997 & 526.512 & 42.119 & -6.783 .890 \\
\hline Observações & 51 & 51 & 51 & 51 & 51 \\
\hline \multicolumn{6}{|c|}{ Valores relativos ao ano de 2003} \\
\hline Média & 36.956 .119 & 6.394 .976 & 34.976 .679 & 15.190 .881 & 615.878 \\
\hline Máximo & 188.918 .883 & 59.630 .138 & 179.481 .484 & 72.748 .768 & 5.522 .369 \\
\hline Mínimo & 1.275 .845 & 84.901 & 1.257 .872 & 44.149 & -566.938 \\
\hline Observações & 51 & 51 & 51 & 51 & 51 \\
\hline \multicolumn{6}{|c|}{ Valores relativos ao ano de 2004} \\
\hline Média & 41.182 .253 & 6.892 .564 & 38.638 .769 & 18.130 .338 & 771.679 \\
\hline Máximo & 199.250 .017 & 52.786 .056 & 193.940 .687 & 97.616 .084 & 7.268 .905 \\
\hline Mínimo & 672.704 & 117.480 & 604.830 & 59.915 & -2.964 .438 \\
\hline Observações & 51 & 51 & 51 & 51 & 51 \\
\hline
\end{tabular}

Fonte: elaboração própria.

Observando os valores na Tabela 1, pode-se verificar grandes distorções relacionados ao porte das cooperativas. Embora existam diversas maneiras de amenizar este problema, optou-se por acomodá-lo com o uso do modelo de retornos variáveis de escala. Dessa forma não se perde informação associado a uma possível fragmentação da amostra.

Os modelos de análise por envoltória de dados serão aplicados de maneira que permita uma análise temporal da dinâmica entre as cooperativas da amostra. Para este fim, considerou-se que os dados das 51 cooperativas dos anos de 2002, 2003 e 2004 pertencem a apenas um período de tempo. O modelo a ser utilizado será o primal e os dados serão tratados com o auxílio do Microsoft Excel.

Após o cálculo dos indicadores de eficiência, as cooperativas são reagrupadas conforme o respectivo ano. Esse artifício permite que se tenha uma mostra maior e, portanto, mais consiste evidenciando a evolução ao longo de três exercícios.Assim, este artifício permite que o cálculo de indicadores de eficiência de maneira mais consistente; pois têm-se um número maior de dados. A sua posterior separação dos dados permite identificar claramente se um dos anos apresenta eficiência superior aos demais. Então, optou-se pela aplicabilidade conjunta de todos os anos.

Com a aplicação dos modelos DEA, pretende-se analisar o grau de eficiência média das cooperativas em cada um dos respectivos exercícios e sua dinâmica evolutiva. Estes valores serão confrontados com um dos principais indicadores de resultados geralmente adotados pelas empresas, o indicador de rentabilidade. No caso das cooperativas, a rentabilidade será calculada pela razão das sobras ou perdas pelo patrimônio líquido.

Do confronto entre indicadores de eficiência e rentabilidade será possível evidenciar se existe algum efeito (linear) da eficiência das cooperativas com a geração de resultados 
financeiros superavitários ou deficitários. É natural se esperar que, de certa forma, a capacidade de geração de receitas (de forma estratégica) esteja associada com a geração de resultados financeiros.

\section{ANÁLISE E DISCUSSÃO DOS RESULTADOS}

Os resultados obtidos através da aplicação dos modelos DEA direcionados para eficiência total e eficiência gerencial são apresentados de forma resumida na tabela 2 . Nesta tabela são identificados os valores médios, desvio padrão, máximo e mínimo para as 51 cooperativas em cada um dos respectivos exercícios. Também, é identificado o número de cooperativas consideradas como eficientes ao logo dos três anos, portanto, percebe-se que em termos de eficiência total as cooperativas estão se mantendo com certa homogeneidade de desempenho, próximo a fronteira eficiente. Assim, têm-se que entre as 51 cooperativas analisadas não há espaço para ineficiências discrepantes.

Tabela 2 - Eficiência total e eficiência gerencial

\begin{tabular}{l|c|c|c}
\hline \multicolumn{1}{c|}{ Eficiência } & $\mathbf{2 0 0 2}$ & $\mathbf{2 0 0 3}$ & $\mathbf{2 0 0 4}$ \\
\hline \multicolumn{4}{|c}{ Eficiência total - Modelo radial - Orientado para inputs - CCR } \\
\hline Média & 0,90 & 0,89 & 0,89 \\
\hline Desvio Padrão & 0,05 & 0,04 & 0,05 \\
\hline Máximo & 1,00 & 1,00 & 1,00 \\
\hline Mínimo & 0,79 & 0,79 & 0,74 \\
\hline Eficientes & 5,00 & 2,00 & 2,00 \\
\hline Eficiência gerencial - Modelo radial-Orientado para inputs - BCC \\
\hline Média & 0,92 & 0,92 & 0,92 \\
\hline Desvio Padrão & 0,05 & 0,05 & 0,05 \\
\hline Máximo & 1,00 & 1,00 & 1,00 \\
\hline Mínimo & 0,80 & 0,79 & 0,75 \\
\hline Eficientes & 7,00 & 6,00 & 7,00 \\
\hline Fonte: elaboração própria.
\end{tabular}

Com base nos valores apresentados na tabela 2, é possível afirmar que as cooperativas estão operando com uma eficiência total média de aproximadamente $90 \%$, ou seja, uma ineficiência de $10 \%$ e que essa eficiência permaneceu praticamente constante em todos os exercícios. Através da aplicação de um simples teste de diferença de média (teste $\mathrm{U}$ ) constatou se que a diferença $(0,90$ - 0,89$)$ não é significativa, fato que pode ser comprovado pela reduzida variabilidade do desvio padrão nos respectivos anos.

Relativo à eficiência gerencial média, pode-se verificar que os indicadores são constantes ao longo do tempo dispensando a utilização de testes estatísticos. De certa forma esses resultados surpreendem, pois evidenciam claramente que a eficiência, em termos médios, está sofrendo pouca interferência de fatores econômicos que estão ocorrendo ao longo do tempo. Porém, outra possível explicação para que o grau de eficiência gerencial media não tenha se alterado ao longo do tempo com desvio padrão estático é que os diversos fatores conjunturais econômicos e políticos estejam afetando de forma idêntica e indistintamente todas as cooperativas.

De forma há elucidar um pouco mais o entendimento da não variabilidade o grau de eficiência média gerencial e da insignificante variação da eficiência média total, a tabela 3 apresenta os valores da decomposição da ineficiência. Nesse caso, o grau de ineficiência total será decomposto em duas partes: a) ineficiência gerencial; e, b) ineficiência de escala. 
Tabela 3 - Decomposição da ineficiência total

\begin{tabular}{l|c|c|c}
\hline \multicolumn{1}{c|}{ Ineficiência } & $\mathbf{2 0 0 2}$ & $\mathbf{2 0 0 3}$ & $\mathbf{2 0 0 4}$ \\
\hline \multicolumn{4}{l|}{ Ineficiência gerencial - Modelo radial - Orientado para inputs } \\
\hline Média & 0,08 & 0,08 & 0,08 \\
\hline Desvio Padrão & 0,05 & 0,05 & 0,05 \\
\hline Máximo & 0,20 & 0,21 & 0,25 \\
\hline Mínimo & 0,00 & 0,00 & 0,00 \\
\hline Eficientes & 7,00 & 6,00 & 7,00 \\
\hline Ineficiência de escala-Modelo radial- Orientado para inputs \\
\hline Média & 0,02 & 0,03 & 0,03 \\
\hline Desvio Padrão & 0,02 & 0,03 & 0,03 \\
\hline Máximo & 0,12 & 0,16 & 0,12 \\
\hline Mínimo & 0,00 & 0,00 & 0,00 \\
\hline Eficientes & 5,00 & 2,00 & 2,00 \\
\hline
\end{tabular}

Fonte: elaboração própria.

Através da análise dos valores constantes na tabela 3, é possível afirmar que a parcela que mais contribui para o grau de ineficiência total é a ineficiência gerencial. Assim, para o ano de 2002, a ineficiência média total foi de $10 \%$ (8\% ineficiência gerencial e $2 \%$ ineficiência de escala). Para os anos de 2003 e 2004 estes valores permaneceram constantes, sendo que a variação da ineficiência de escala é não significativa estatisticamente (teste U). De posse desses resultados, constata-se que a contribuição da ineficiência de escala na ineficiência total é menor do que a contribuição da gerencial.

$\mathrm{Na}$ Tabela 4, são apresentados os valores médios das ociosidades encontradas na estrutura de capital das cooperativas, bem como a ociosidade nos gastos operacionais. Observe que esses valores são representativos das ociosidades, ou seja, estão além dos valores que podem ser reduzidos através da melhoria identificados pelo grau de eficiência das cooperativas (eficiência total e gerencial). Em outras palavras, estes valores são representativos das folgas dos modelos análise de eficiência. Também são evidenciados o número de cooperativas que apresentaram valores significativos de ociosidade em cada variável analisada.

Tabela 4 - Ociosidade da estrutura de capital e gastos operacionais

\begin{tabular}{l|r|r|r}
\hline \multicolumn{1}{c}{ Ociosidade } & $\mathbf{2 0 0 2}$ & $\mathbf{2 0 0 3}$ & $\mathbf{2 0 0 4}$ \\
\hline Ociosidade de Exigibilidades & 1.707 .657 & 5.436 .669 & 6.524 .022 \\
\hline Média & 25 & 36 & 35 \\
\hline Cooperativas com ociosidade & \multicolumn{3}{|}{} \\
\hline Ociosidade de Patrimônio Líquido & 81.067 & 91.400 & 68.049 \\
\hline Média & 6 & 7 & 9 \\
\hline Cooperativas com ociosidade & 0 & 0 & 0 \\
\hline Ociosidade de Gastos Operacionais & 0 & 0 & 0 \\
\hline Média & 0
\end{tabular}

Observando-se os valores apresentados na tabela 4, constata-se que a ociosidade ocorre apenas na estrutura de capital (exigibilidade e patrimônio líquido) estando ausente nos gastos operacionais. Observando os valores das ociosidades ao longo dos anos, verifica-se que os relacionados às exigibilidades apresentam uma tendência de crescimento substancial enquanto que os relativos ao patrimônio líquido oscilaram dentro de uma faixa estreita de valores, não apresentando tendência de crescimento.

As Figuras 3 e 4 ilustram de forma gráfica a presença da ociosidade das exigibilidades e da ociosidade do patrimônio líquido, respectivamente, para cada uma das 51 cooperativas. 
Nestes gráficos as ociosidades relativas aos anos de 2002 são identificadas pelas primeiras 51 observações, as próximas observações são representativas das ociosidades do ano de 2003 e as últimas 51 observações representam as ociosidades das cooperativas no ano de 2004.

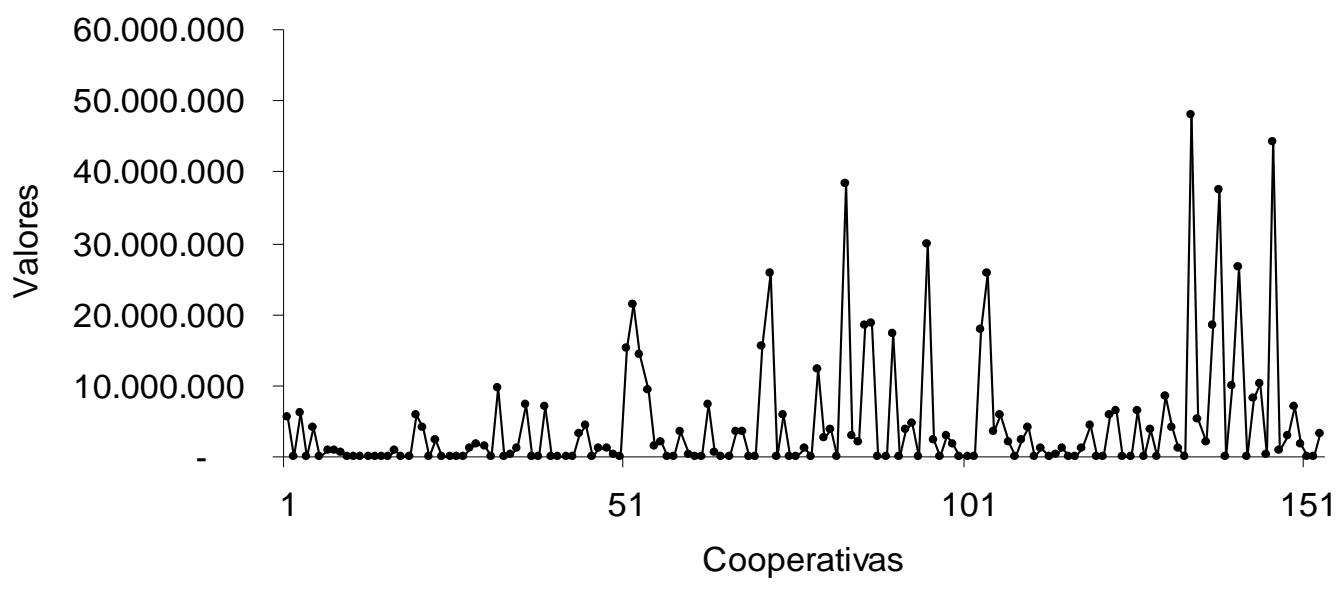

Figura 3 - Ociosidade das exigibilidades no período 2002-2004 Fonte: elaboração própria.

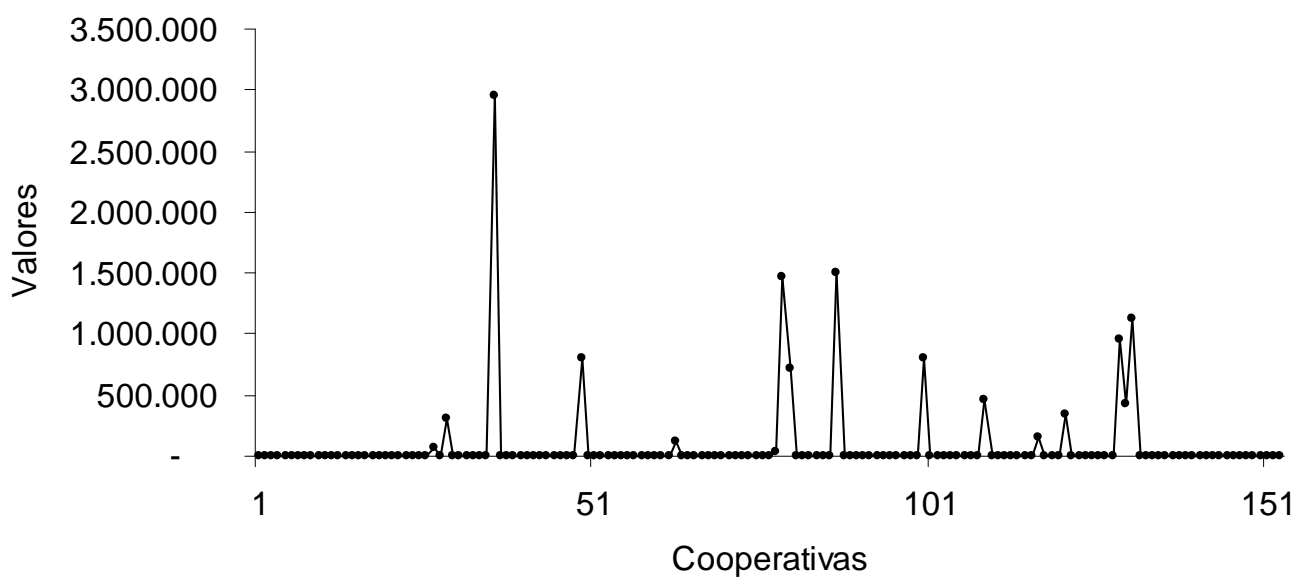

Figura 4 - Ociosidade do patrimônio líquido no período 2002-2004 Fonte: elaboração própria.

A análise visual das Figuras 3 e 4 evidenciam claramente que o problema da ociosidade das exigibilidades é mais grave no setor das cooperativas. Pois se constata que o excesso de exigibilidades atinge um maior número de cooperativas, além de se apresentarem com valores mais significativos e possuírem tendência de crescimento ao longo do período, o que não ocorre com a ociosidade do patrimônio líquido.

Como última análise a ser realizada com os resultados do estudo, a Tabela 5 apresenta os valores relativos à correlação entre indicadores de eficiência total, eficiência gerencial e rentabilidade. Aqui a idéia básica é verificar se existe algum tipo de relacionamento linear entre eficiência e rentabilidade, ou seja, uma cooperativa eficiente implica em uma cooperativa rentável (no sentido de sobras), portanto sobras ou perdas não foi incluído nos modelos de eficiência. A análise é realizada para cada um dos anos e para o período completo. Dessa forma pode-se isolar possível correlação espúria. 
Tabela 5 - Correlação entre eficiências e rentabilidade

\begin{tabular}{l|c|c|c}
\hline \multicolumn{1}{c|}{$\begin{array}{c}\text { Indicadores das } \\
\text { Cooperativas }\end{array}$} & $\begin{array}{c}\text { Eficiência } \\
\text { Total }\end{array}$ & $\begin{array}{c}\text { Eficiência } \\
\text { Gerencial }\end{array}$ & Rentabilidade \\
\hline Ano de 2002 & 1,00 & & \\
\hline Eficiência Total & 0,92 & 1,00 & \\
\hline Eficiência Gerencial & 0,54 & 0,56 & 1,00 \\
\hline Rentabilidade & & & \\
\hline Ano de 2003 & 1,00 & & \\
\hline Eficiência Total & 0,76 & 1,00 & 1,00 \\
\hline Eficiência Gerencial & $-0,05$ & $-0,12$ & \\
\hline Rentabilidade & & & 1,00 \\
\hline Ano de 2004 & 1,00 & & \\
\hline Eficiência Total & 0,82 & 1,00 & \\
\hline Eficiência Gerencial & 0,08 & 0,06 & 1,00 \\
\hline Rentabilidade & & & \\
\hline Período 2002-2004 & 1,00 & & \\
\hline Eficiência Total & 0,83 & 1,00 & \\
\hline Eficiência Gerencial & 0,21 & 0,18 & \\
\hline Rentabilidade & &
\end{tabular}

Fonte: elaboração própria.

Com base nos valores apresentados na Tabela 5 e usando o valor de 0,7 como parâmetro de alta correlação, constata-se que não existe nenhum tipo de relacionamento linear forte entre os indicadores de eficiência com o indicador de rentabilidade. A única relação significativa, porém fraca, entre eficiência e rentabilidade ocorreu em 2002, porém não se manteve nos próximos exercícios. Dessa forma, indicadores de eficiência e rentabilidade se apresentam de forma desassociada e independente, pelo menos para a amostra analisada.

\section{CONSIDERAÇÕES FINAIS}

A análise por envoltória de dados já possui utilização consolidada em diversas áreas, em vários países. No Brasil, seu uso é relativamente recente. Esse trabalho utilizou a análise por envoltória de dados para avaliar o grau de eficiência relativa em cooperativas ao longo de três anos. O foco do trabalho foi sobre o grau de eficiência total, eficiência gerencial e eficiência de escala.

Os resultados obtidos permitem afirmar que o conjunto de cooperativas analisadas está operando de maneira homogênea e com grau de eficiência relativamente elevado ao longo de todo o período. Identificou-se que o maior problema não está relacionado com o grau de eficiência, mas com o crescente aumento de ociosidade na estrutura de capital das cooperativas. Outro aspecto importante está relacionado com o fato de não ter sido identificado uma relação significativa entre indicadores de eficiência e rentabilidade.

Contudo, deve-se salientar que, na análise quantitativa, seu resultado está intrinsecamente relacionado à escolha das variáveis. Em função do processo de seleção das variáveis, a modelagem também pode apresentar um aspecto quantitativo. Por isso mesmo, este trabalho não pretende tomar os percentuais obtidos como definitivos, mas demonstrar a utilidade de uma ferramenta bastante apropriada para auxiliar no processo de avaliação, comprovando a possibilidade de envolver dados financeiros de maneira diferentemente ponderada com o objetivo de tornar a análise mais flexível e abrangente.

Cabe lembrar que o modelo DEA foi executado com ênfase na redução de inputs e não no aumento dos outputs. Mas, apesar disso, muitas vezes a combinação linear de uma 
determinada unidade de avaliação com seus pares só é possível através do aumento de um ou mais output. Devido a esse fato, em alguns casos há necessidade de diminuição do montante de investimentos como, por exemplo, redução do patrimônio líquido, hipótese quase impraticável.

Outro aspecto que deve ser observado é o fato de que os inputs e outputs não são uniformes, e que o modelo aplicado neste estudo não considera esta característica. A capacidade de trabalho das cooperativas é diferente, a distinção de cada cooperativa possui certas particularidades (umas estão em centros privilegiados, outras, fora destas áreas). Por isso, fica a ressalva de que as metas não devem ser examinadas sem uma compreensão das características de cada unidade.

Apesar destes aspectos, o modelo de análise por envoltória de dados apresenta-se flexível, permitindo incluir e excluir variáveis facilmente, bem como incluir e excluir unidades. Outra vantagem é a de poder incorporar vários inputs e outputs sem pesos predeterminados associados a eles. Além disso, o modelo aponta as melhores práticas e os melhoramentos e não apenas sinaliza a não eficiência.

Certas metas apresentadas neste modelo podem ser consideradas inviáveis, porém dão um indicativo da direção proposta para o alcance da eficiência relativa no conjunto de cooperativas. Reduzir investimentos ou aumentar receitas, por exemplo, não depende somente de cada unidade, mas de interesse ou necessidade da empresa ou dos sócios. Muitas cooperativas receberam indicativos para incremento na receita ou redução de investimentos, porém isto não seria possível sem um estudo detalhado das condições e recursos que cada cooperativa possui. Este indicativo deve ser tomado apenas como uma direção para que, na medida do possível, a administração possa planejar um incremento de atividades nesta área.

Concluindo, deve-se destacar que este estudo não teve a pretensão de apresentar um modelo perfeito, mas de realizar uma avaliação das cooperativas agropecuárias sob uma perspectiva de grande flexibilidade. Neste sentido é necessário ressaltar que o processo de avaliação deve ser mais um processo de construção do que um processo de mera mediação de resultados e variáveis.

\section{REFERÊNCIAS}

ANTONELLO, V. Crise e mudança nas cooperativas empresarias rurais: ascensão ou falência? Perspectiva Econômica, São Leopoldo, v.30, n.91, p.47-63,1995.

ANTONIALLI, L.M. Influência da mudança de gestão nas estratégias de uma cooperativa agropecuária. In: ENANPAD, 22., 1998, Foz do Iguaçu. Anais... Rio de Janeiro: ANPAD, 1998.

ANTONIALLI, L.M. Modelo de gestão e estratégias: o caso de duas cooperativas mistas de leite e café de Minas Gerais. 163 fls. Tese (Doutorado em Administração) - Universidade de São Paulo, São Paulo, 2000.

AVELAR, J.V.G; POLEZZI, A.O.D.; MILIONI, A.Z. On the evaluation of Brazilian landline telephone services companies. Pesquisa Operacional/Brazilian Operations Research Society, v. 22, n. 2, p. 231-247, 2002.

BASTOS, A. T. A difícil modelagem institucional da cooperação: uma análise do cooperativismo agropecuário do norte do Ceará. In: ENANPAD, 26., Salvador. Anais... Rio de Janeiro: ANPAD, 2002.

BERNARDO, E.E.R. A crise no cooperativismo. In: ENANPAD, 20., 1996, Angra dos Reis. Anais... Angra dos Reis: ANPAD, 1996. 
BENECKE, D.W. As cooperativas e suas condições de êxito. In: PINHO, D. B. (org.). Manual de cooperativismo: administração de cooperativas. São Paulo: CNPq, 1982.

BIALOSKORSKI NETO, S.; ZYLBERSZTAJN. D. Cooperativismo: economia de empresas e estratégias. Perspectiva Econômica, São Leopoldo, v. 29, n. 84, p. 7-22, 1994.

BIALOSKORSKI, Neto Sigismundo. Ensaios em cooperativismo. Ribeirão Preto: Universidade de São Paulo, 1998.

BRASIL. Constituição da República Federativa do Brasil. Brasília: Senado Federal, Centro Gráfico, 1988.

CATELLI, A. (Coord.). Controladoria: uma abordagem da gestão econômica - GECOM. São Paulo: Atlas, 1999.

CHARNES, A., COOPER, W.W., e RHODES, E. Measuring the efficiency of decision making units. European Journal of Operational Research, v. 2, n. 6, p. 429-444, 1978. http://dx.doi.org/10.1016/0377-2217(78)90138-8

CHIRIKOS, T.N., SEAR, A.M. Measuring hospital efficiency: a comparison of two approaches. Health Services Research. v. 34, n. 6, p.1389-1408, 2000.

COELlI, T.; PRASADA RAO, D.S.; BATTESE, G.E. An introduction to efficiency and productivity analysis. Massachussets: Kluwer Academic Publishers, 1998.

COOK, M. L. The evolution of U.S. agricultural cooperative financial strategies. In: UNIVERSITY OF SÃO PAULO'S INTERNATIONAL AGRIBUSINESS SEMINAR. 1994, Águas de São Pedro. 1994. Anais... São Paulo-Brazil: PENSA/USP, 1994.

COOPERATIVISMO: dirigentes discutem o futuro do setor e a própria capacitação. Balde Branco, São Paulo, v.33, n.393, p.45-47, 1997.

COSTA SANTOS, R. C. Cooperativa agropecuária Holambra: uma organização em mudança. In: ZYLBERSZTAJN, D. Estudos de caso em agribusiness. Porto Alegre: Ortiz, 1993.

CRÚZIO, H. de O. Problemas organizacionais e administrativos das cooperativas agroindustriais e agropecuárias no estado da Bahia. Dissertação (Mestrado em Administração Rural) - Escola Superior de Agricultura de Lavras, Lavras, 1989.

DE LEONE, R., LAZZARI, C. Measuring efficiency using data envelopment analysis. Rendiconti del Circolo Matematico di Palermo, 58, Serie II. 1999.

DE MASY, R. C. Moderna gestión de empresas cooperativas agrarias. Valencia: Conselleira de Trabajo del País Valenciano. 1980.

EMPEL, G. Van. Future outlooks for european cooperatives in a dymamic agri and food environment. In: INTERNATIONAL AGRIBUSINESS SEMINAR - PENSA. Canela, 1996. Anais... Canela-Brazil: PENSA/USP, 1996.

GRANTHOM, J.C. Análise administrativa de uma organização cooperativa: uma aplicação da teoria dos sistemas. 93 fls. Dissertação (Mestrado em Administração Rural) - Escola Superior de Agricultura de Lavras, Lavras, 1987.

IRION, João Eduardo. Cooperativismo e economia social. São Paulo: STS, 1997.

IUDÍCIBUS, S. (Coord.). Equipe de Professores da Faculdade de Economia, Administração e Contabilidade da USP. Contabilidade introdutória. 9. ed. São Paulo: Atlas, 1998.

JANK, M. S.; NASSAR, A. M. Agribusiness e cooperativas no Mercosul. Perspectiva Econômica, São Leopoldo, v. 30, n. 91, p. 13-32, out./dez. 1995. 
JANK, M. S.; GALAN, V.B. ITAMBÉ: o desafio das cooperativas no novo cenário brasileiro. São Paulo: FEA/USP, 1997.

KASSAI, S. Utilização da análise por envoltória de dados (DEA) na análise de demonstrações contábeis. 2002. 318 fls. Tese (Doutorado em Controladoria e Contabilidade) - Universidade de São Paulo, 2002.

LEGISLAÇÃO COOPERATIVISTA E RESOLUÇÕES DO CONSELHO NACIONAL DE COOPERATIVISMO. 6. ed. Brasília: CNC/OCB/MAA/SDR/ DENACOOP, 1996.

MACEDO, M. A. S.; MACEDO, H. D. R. Avaliação de performance financeira através da Análise Envoltória de Dados: um estudo de caso em unidades de negócio. CLADEA, 38., 2003, Lima. Anais ... Lima, Peru: CLADEA, 2003.

MEGIDO, J.L.T. Cooperativa Batavo. In: ZYLBERSZTAJN, D. (Coord.). Estudos de caso em agribusiness: o processo de tomada de decisão nas empresas brasileiras. Porto Alegre: Ortiz, 1993.

MOLINERO, Cecilio Mar; WORACKER, David. Data Envelopment Analysis: a nonmathematical introduction. Journal of the Operational Research Society, v. 9, n. 4, p. 22-28, Out./Dec., 1996.

ORGANIZAÇÃO DAS COOPERATIVAS BRASILEIRAS (OCB). Disponível em: <http://www.ocb.org.br>. Acesso em: 10 abr. 2005.

ORGANIZAÇÃO DAS COOPERATIVAS DO ESTADO DO RIO GRANDE DO SUL (OCERGS). Autogestão: a função do cooperado - como organizar-se. Porto Alegre: OCERGS, 1992.

ORGANIZAÇÃO DAS COOPERATIVAS DO ESTADO DO RIO GRANDE DO SUL (OCERGS). Manual de orientação para a Constituição de Cooperativas, 1999.

OLIVEIRA, T. C. Cooperativas de trabalho: instruções para organizações. São Paulo: Secretaria de Agricultura e Abastecimento, 1996.

PEREIRA, A. C. Contribuição à análise e estruturação das demonstrações financeiras das sociedades cooperativas brasileiras: ensaio de abordagem social, 325 fls. Tese (Doutorado em Contabilidade) - Universidade de São Paulo, São Paulo, 1993.

PINHO, Diva Benevides. Economia e cooperativismo. São Paulo: Saraiva, 1972.

POLÔNIO, Wilson Alves. Manual das sociedades cooperativas. 2 ed. São Paulo: Atlas, 1999.

RISTOFF, Dilvo I. Avaliação institucional: pensando princípios. In: BALZAN, Newton César; DIAS SOBRINHO, José (Orgs.). Avaliação institucional: teorias e experiências. São Paulo: Cortez, 1995.

SCHMIDT, P. Controladoria: agregando valor para a empresa. Porto Alegre: Bookman, 2003.

SCHULZE, E. Estrutura do poder em cooperativas. Perspectiva Econômica, São Leopoldo, v. 22, n. 59, p. 49-76, jun./dez. 1987.

SILVA, J. P. Análise financeira das empresas. 6. ed. São Paulo: Atlas, 2004.

ZHU, Joe. Multi-factor performance measure model with application to Fortune 500 companies. European Journal of Operational Research. n. 123, v. 1, p. 105-124, 2000. http://dx.doi.org/10.1016/S0377-2217(99)00096-X 
ZYLBERSZTAJN, D. Surge uma nova geração de cooperativas agrícolas. São Paulo: FEA/USP/PENSA, 1996.

ZYLBERSZTAJN, D. Estruturas de governanças e coordenação do agribusiness: uma aplicação da nova economia das instituições. 237 fls. Tese (Livre -Docência). São Paulo: [s.n.], 1995.

VERHEIJEN, J.A.G.; HEIJBROEK, A.M.A. Cooperatives in changing market conditions. Rabobank Nederland: Agrobusiness Research Departament, 1995. 